\title{
Chronological Change of Energy Input for Squid Angling in Japan 1956-1983
}

\author{
Kaname Sato, ${ }^{* 1}$ Hisahiko Watanabe, ${ }^{* 2}$ Masanobu Ishikawa, ${ }^{* 2}$ \\ and Hayao Akizawa*1
}

(Received July 19, 1989)

\begin{abstract}
Energy input for squid angling in Japan was examined using census data, i.e., Economy of Fisheries Establishments. The fuel oil consumption per catch was little dependent either on the tonnage of boats or on the location of fishing area. Fuel oil consumption per catch, which was almost constant at $0.2 \mathrm{l} / \mathrm{kg}$-catch in 1950's, and was $0.3 \mathrm{l} / \mathrm{kg}$-catch in 1960 's made a rise in 1970 . The rise continued until it reached a maximum of $2 / / \mathrm{kg}$-catch in around 1978, after that a gradual decrease was observed. The rise was little affected by the skyrocketing rise of oil prices but was more related to the sudden drop of catch per fishing day per boat which took place in 1970 . During this period of time, squid angling operated with a $50-100 \mathrm{t}$ boat increased greatly fishing days per voyage (five-fold) and fuel oil consumption per fishing day (twice). The increase in fuel oil consumption is ascribed to the increase of power of fishing lamps.
\end{abstract}

Food production in the industrialized society deeply depends on the consumption of fossil energy

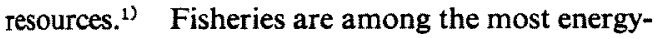
intensive industries concerned with food production.2) Watanabe and OKubo ${ }^{3)}$ estimated the total energy input as well as energy input per catch in $\mathbf{1 9 8 0}$ for each fishery sorted by fishery type as well as by spiecies of fish. The estimated grand total of energy input for marine fisheries in Japan was $6.0 \times 10^{13} \mathrm{kcal}$. The estimated energy input per kilogram of catch varied greatly from $3.5 \times$ $10^{4} \mathrm{kcal} / \mathrm{kg}$-catch (tuna long line) to $0.05 \times 10^{4}$ $\mathrm{kcal} / \mathrm{kg}$-catch (beach seine).

Energy input per catch depends mostly on the method of fishing and the abundance of fish resources. Energy input in fisheries has been increased due to the reinforced efforts for catching fish induced by a rise in fish price, progress in technology and decrease in resource productivity.

In the present paper, energy input for squid angling in Japan was analized. Chronological change of energy input for 28 years was examined and causes for the change were discussed.

\section{Materials and Methods}

We used a series of census data: Economy of Fisheries Establishments (EFE) ${ }^{* 3}$ for 1956 through to 1983. EFE is an annual report published by the Japanese government based on a sampling survey on the nationwide average of each fisheries management unit.

In EFE, annual fisheries expenditures in price per fisheries management unit in detailed items are available as well as selected information concerning fisheries activities such as the kind of fishing type, the tonnage of boats, the amount of catch and the number of fishing days. The amount of fuel oil consumption was estimated by the fuel oil expenditure divided by the fuel oil price.

Because the ratio of direct energy input (fuel oil input) to the total energy input came to $90 \%$ and more, ${ }^{3)}$ fuel oil input was used as the index for total energy input.

In EFE, data are reported on the economy of squid angling managment units which are sorted into several groups according to both the tonnage of boats and the fishing area in the Japanese waters. The tonnage of boats are classified into

*1 Department of Marine Science and Technology, Tokyo University of Fisheries, Konan, Minato, Tokyo 108; Japan（東京水産大学海洋生産学科).

*2. Department of Food Science and Technology, Tokyo University of Fisheries, Konan, Minato, Tokyo 108 , Japan（東京水産大学食品生原学科）.

*3 Statistics and Information Department, Ministry of Agriculture, Forestry and Fisheries: Economy of Fisheries Establishments, Norin Tokei Kyokai, Tokyo. The issues for 1956 through to 1983. 


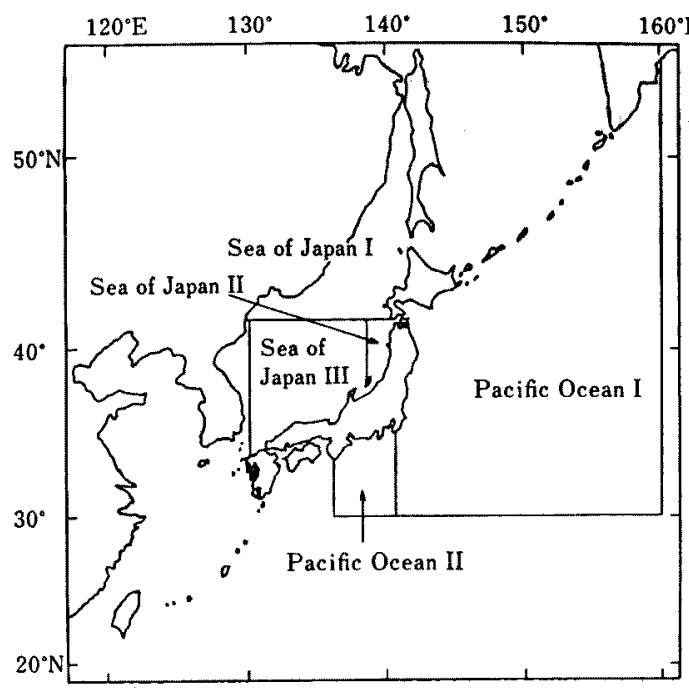

Fig. 1. Fishing areas in the Japanese waters.

five levels: $10-30 \mathrm{t}, 30-50 \mathrm{t}, 50-100 \mathrm{t}, 100-200 \mathrm{t}$, and $200-500 \mathrm{t}$. Fishing areas in the Japanese waters are divided into five areas: the Sea of Japan I, the Sea of Japan II, the Sea of Japan III, the Pacific Ocean I, and the Pacific Ocean II (Fig. 1).

\section{Results and Discussion}

The litters of fuel oil consumption per kilogram of catch in 1983 and in 1974 are plotted in Fig. 2 against the tonnage of boats operated in selected fishing areas. Fig. 2 tells us that the fuel oil consumption per catch was little dependent either on the tonnage of boats or on the location of fishing area.

The chronological change of fuel oil consumption per catch through twenty eight years between 1956 and 1983 is shown in Fig. 3. Fig. 3 tells us that the chronological change of fuel oil consumption per catch shows a similar behavior irrespective of the tonnage of boats. The fuell oil consumption per catch was around $0.2 / / \mathrm{kg}$-catch in 1950's and around $0.3 \mathrm{l} / \mathrm{kg}$-catch in 1960's. A rise made at 1970 continued until it reached a maximum of $2 \mathrm{l} / \mathrm{kg}$-catch at around 1979 , after that a gradual decrease was observed.

It is interesting that the fuel oil consumption per catch has been very little affected by the skyrocketing rise of fuel oil price which took place in 1973 and 1979 due to the Arab oil embargo. What affected the fuel oil consumption per catch was the abundance of fish resources. The rise of fuel oil consumption per catch started in 1970 was obviously related to the sudden drop of the catch per fishing day per boat which took place in 1970 . Thereafter no recovery was observed. (Fig. 4). The drop of the catch per fishing day per boat indicates the fishing grounds are suffering from exhaustion. The remarkable reduction in the catch per fishing day per boat in 1970's and 1980's did not necessarily mean the decrease in the total catch of squids in the Japan waters: the year average of total catch retained a high level of 500
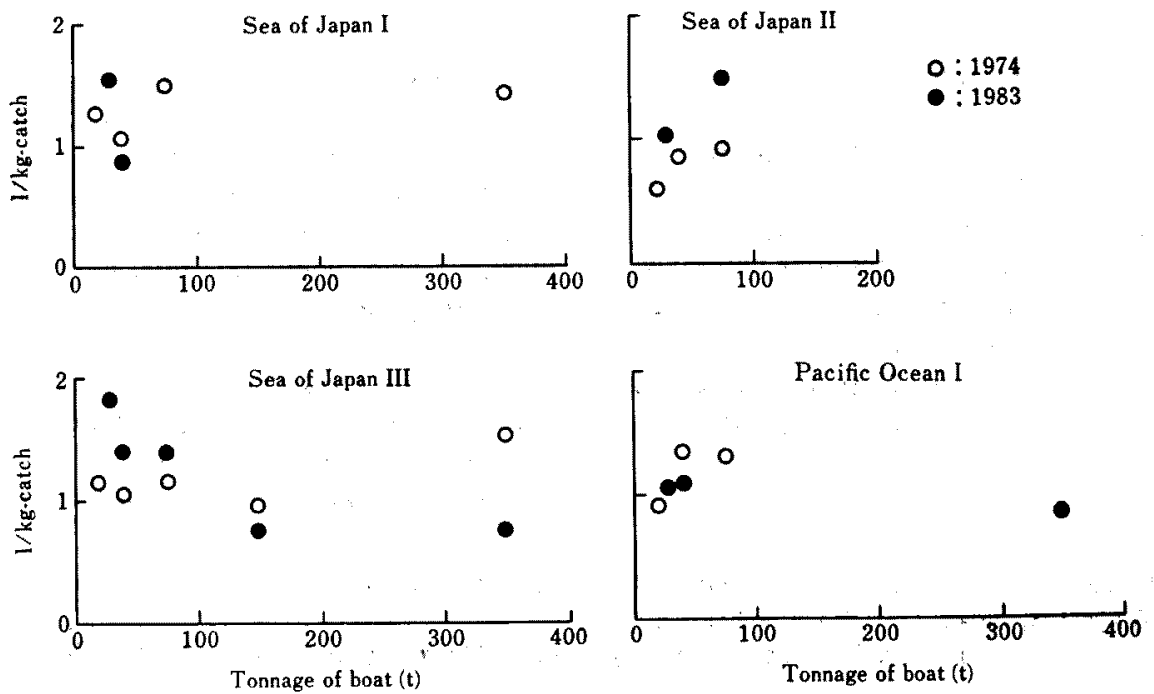

Fig. 2. Fuel oil consumption for squid angling per kilogram of catch vs. tonnage of boats operated in the selected areas in the Japanese waters. 


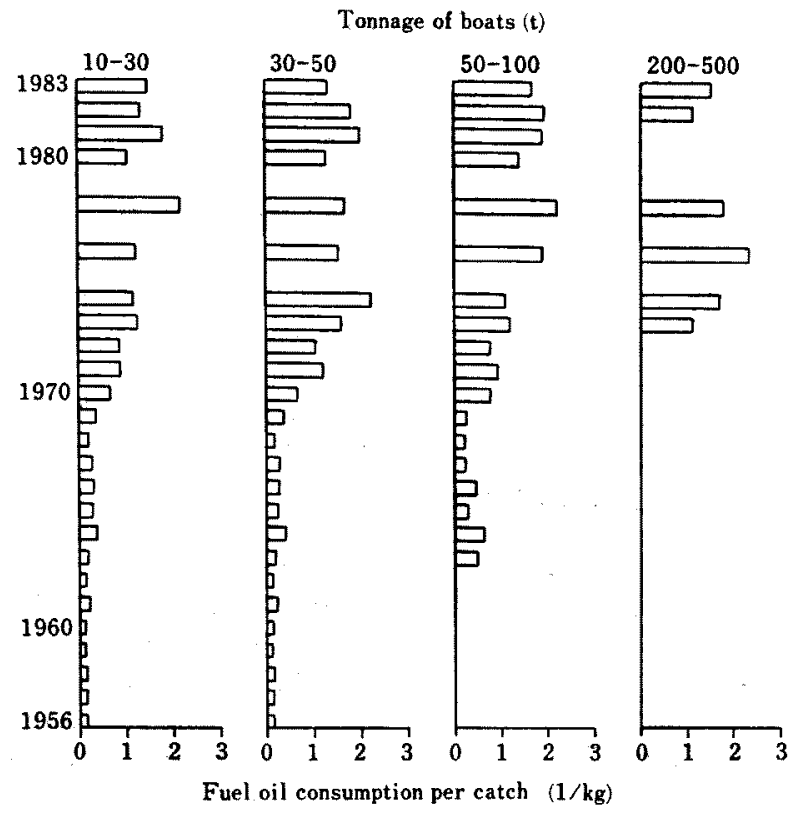

Fig. 3. Chronological change of fuel oil consumption per catch for squid angling operated with boats of selected tonnage. Data in some years are not available in EFE.

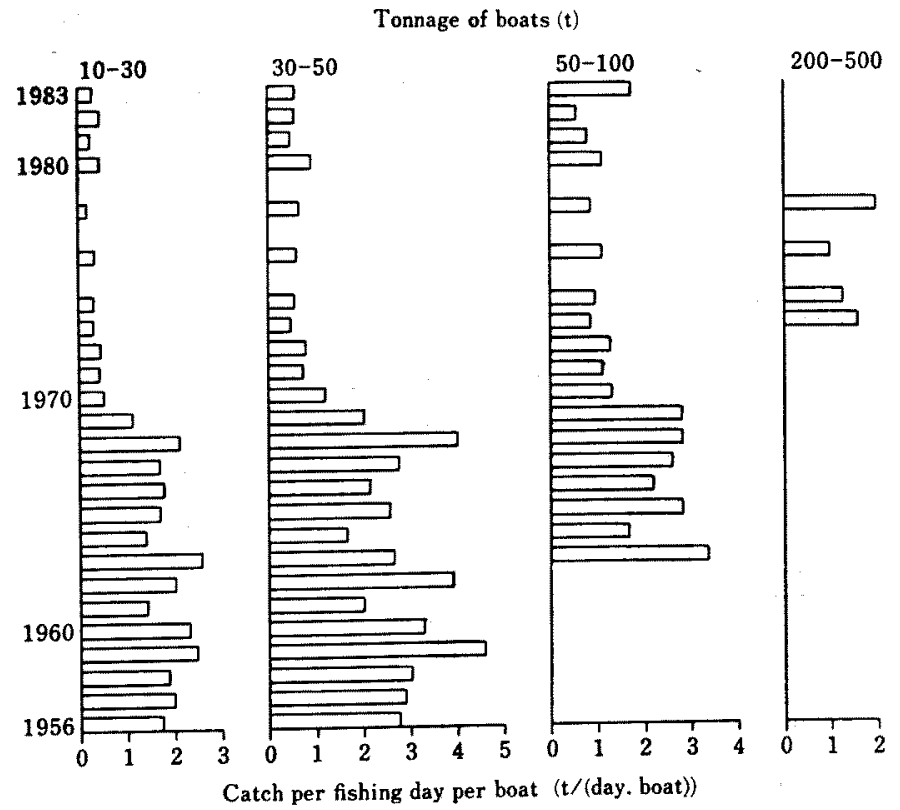

Fig. 4. Chronological change of catch in squid angling per fishing day per boat. Data in some years are not available in EFE.

600 thousand tonnes (Fig. 5).*

When it was linked with the drop of catch per fishing day per boat, the extreme rise of squid price started at around 1970 stimulated fishermen to enhance their efforts for catching squids. The way of enhancing their efforts were different

* Statistics and Information Department, Ministry of Agriculture, Forestry and Fisheries: Fisheries and Aquaculture Production, Norin Tokei Kyokai, Tokyo. The issues for 1941 through to 1941. 
from one management unit to another. The squid angling operated with a $30-50 \mathrm{t}$ boat and that with a $50-100 \mathrm{t}$ boat increased the fishing

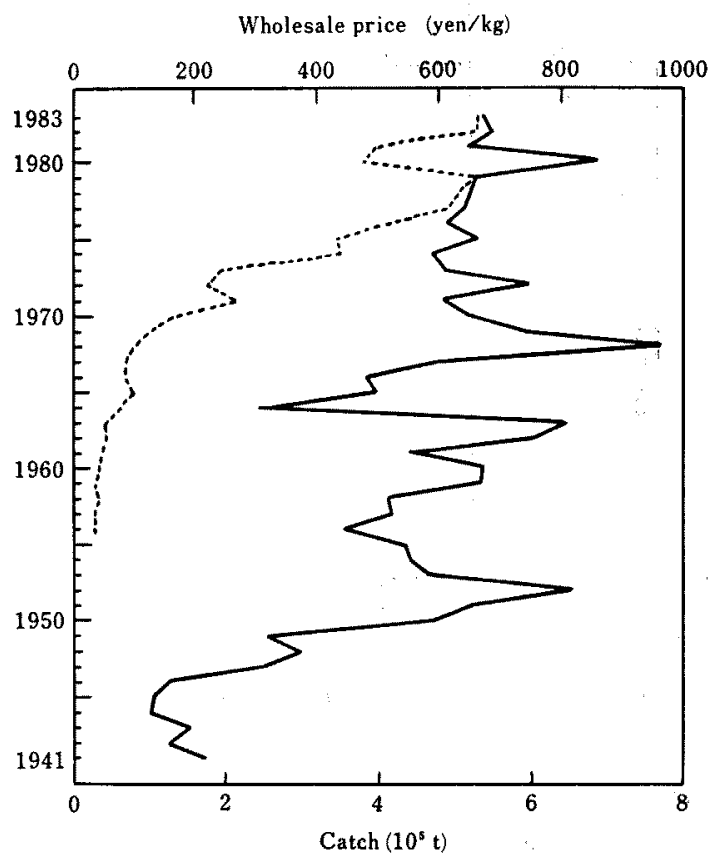

Fig. 5. The trend of total amount of squid catch (solid line)and its whole-sale price (dotted line) in Japan. days per voyage by five to seven times in 1970's (Fig. 6). They seemed to increase fishing days in order to maintain the amount of squid catch. Squid angling operated with a $10-30 \mathrm{t}$ boat, in contrast, kept on one day voyage. Fishermen who kept on one day voyage seemingly came over the difficulty by selling their catch at high prices. The squid put on the market within one day after its catch could have been sold at especially high prices since the squid could be accepted as valuable materials for raw fish dishes when it was distributed without freezing to avoid freeze deterioration.

Concerning the fuel oil consumption per fishing day per boat, on the other hand, no change was observed at around 1970 for squid angling operated with a $10-30 \mathrm{t}$ boat as well as a $30-50 \mathrm{t}$ boat (Fig. 7). Squid angling with a boat of 50-100 t, however, made a considerable rise in fuel oil consumption per fishing day per boat in 1970's.

This rise in the 1970's for 50-100 t boats can be attributed to the increase of the power of the fishing lamps. A survey") on 60-80 $t$ squid angling boats reported that the average power of fishing lamp, which was $40 \mathrm{kw}$ per boat in 1969 , increased year by year until it quadrupled to $160 \mathrm{kw}$ in 1974 . The fuel oil consumption for $50-100 \mathrm{t}$ boats was $840 l /$ (day. boat) in 1969 (Fig. 7). When we assume fishing lamps consume $20 \%$ of total fuel

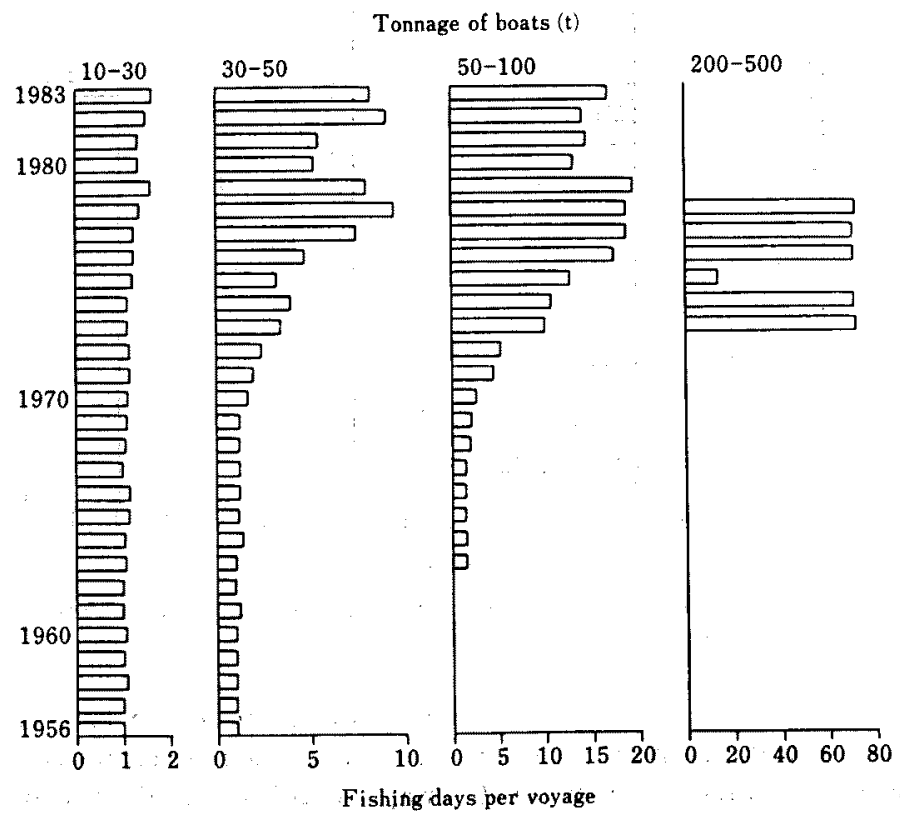

Fig. 6. Chronological change of fishing days per voyage in squid angling. Data in some years are not available in EFE. 


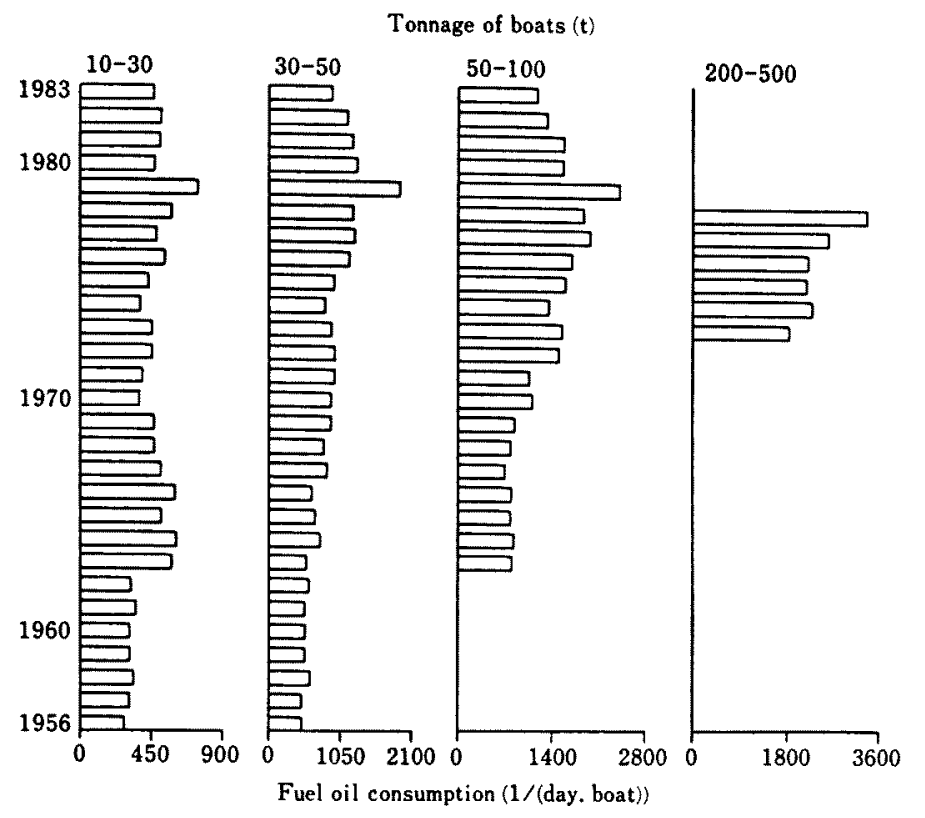

Fig. 7. Chronological change of fuel oil consumption per fishing day per boat.

oil input, ${ }^{5)} 168 l /$ (day. boat) was for fishing lamps and the rest, $672 l /($ day. boat), was for others such as cruise, angling machines, freezers, and etc. If the fuel oil consumption for fishing lamps is quadrupled to $672 l /($ day. boat) and added to the fuel oil consumption for others, the total fuel oil consumption comes up to $1344 /$ (day. boat) which coincides with the value for the fuel oil consumption in 1974 shown in Fig. 7. $\left(1.36 \times 10^{3} / /\right.$ (day. boat)). The survey) also reported that the use of energy-saving fishing lamps, halogen lamps, started in the early 1980's. This could be the cause of the gradual decrease of fuel oil consumption in 1980's. No data on fishing lamps for other tonnage of boats are available.

\section{References}

1) D. Pimentel and M. Pimentel: Food, Energy and Sosiety, Edward Arnold, London, 1979, pp. $1 \sim 113$.

2) Resources Research Council, Bureau of Science and Technology: The Life Cycle Energy, Printing Bureau, Ministry of Finance, Tokyo, 1979. pp. 44 45.

3) H. Watanabe and M. Okubo: Nippon Suisan Gakkaishi, 55, 25-33 (1989).

4) M. Ogura: Suisan Sekai: 32, 60-64 (1983).

5) M. Ishikawa, K. Sato, H. Akizawa, Y. Sakai, and and H. Watanabe: Nippon Suisan Gakkaishi, 53, 1525-1531 (1987). 